\title{
Investigation of VO-salophen complexes electronic structure
}

\author{
Simone Bertini ${ }^{\text {a }}$, Alessia Coletti ${ }^{\text {b }}$, Barbara Floris ${ }^{\text {a }}$, Valeria Conte ${ }^{\mathrm{a}, *}$, Pierluca Galloni ${ }^{\mathrm{a}, *}$ \\ a Dipartimento di Scienze e Tecnologie Chimiche, Università di Roma "Tor Vergata", Via Ricerca Scientifica snc, 00133 Roma, Italy \\ b Dipartimento di Chimica, Materiali e Ingegneria Chimica G. Natta, Politecnico di Milano, via L. Mancinelli 7, 20131 Milano, Italy
}

\section{A R T I C L E I N F O}

Article history:

Received 20 November 2014

Received in revised form 4 March 2015

Accepted 4 March 2015

Available online 13 March 2015

\section{Keywords:}

Vanadium complexes

Electronic density

Substituent effects

\begin{abstract}
A B S T R A C T
Vanadyl $N, N^{\prime}$-bis(salicylidene)-o-phenylenediamine (salophen) complexes have been extensively investigated by cyclic voltammetry, UV-visible spectroscopy and theoretical calculations in MeCN, THF (tetrahydrofuran) and DMF ( $N, N$-dimethylformamide), in order to elucidate the overall factors that influence the electronic density of the metal and therefore the properties of these complexes in various applications. Different substituents were introduced into the salophen skeleton to change the vanadium electron density. Results obtained and here presented showed that the substituents influence the metal electronic character in a way that cannot be easily predicted by considering only the electronic effect. Similarly, the solvent polarity or coordination ability affects the metal complex properties in an unpredictable way. Therefore, experimental and theoretical data here collected are a powerful tool to a priori design salophen ligands to obtain vanadyl complexes having the specific electronic properties suitable for desired applications.
\end{abstract}

(c) 2015 Elsevier Inc. All rights reserved.

\section{Introduction}

Vanadium is an abundant, inexpensive and non-toxic metal naturally involved in different mechanisms of biological systems, as it is already known since almost forty years [1-3]. For example, vanadium was found in the active site of haloperoxidases and nitrogenases, as counter ion of DNA and RNA, as an active player in the inhibition of the Na, $\mathrm{K}$ ATPase, in the photocleavage of proteins and in insulin regulated processes [1-3], thus deserving the interest shown so far by biochemists. Moreover, its rich coordination chemistry, in different oxidation states, makes vanadium an extremely versatile metal for synthetic and catalytic chemical applications [4-7]. In fact, vanadium is currently used, mainly in its pentoxide form, to catalyze a number of industrial production processes or as a strengthening agent in alloys [8]. Inspired by the coordination chemistry of natural systems, among a wide range of synthetic ligands, vanadium has been successfully used to form stable complexes with salen and salophen ligands both in its IV and V oxidation states [9-11].

Salen and salophen ligands are Schiff bases obtained from the easy condensation of two molecules of salicylaldehydes with ethylenediamine or 0 -phenylenediamine, respectively [12]. As Schiff bases, they are able to form stable complexes with different metals in various oxidation states. Salen and salophen complexes have been principally applied as catalysts for a variety of metal catalyzed transformations of organic substrates, in which the ligand influences the reactivity of the metal center in terms

\footnotetext{
* Corresponding authors. Fax: + 390672594328.

E-mail addresses: valeria.conte@uniroma2.it (V.Conte), galloni@scienze.uniroma2.it (P. Galloni)
}

of yield and selectivity. Recently, Schiff base derivatives are emerging as tunable and adaptable chromophore ligands to such an extent that they are tested, for example, as luminescent labeling agent [13], as materials for OLED (organic-light-emitting-diode) technology [14], as probes for cell imaging systems [15]. In this field, the possibility to modulate the ligand substitution is a powerful tool to tune the light absorption and emission behavior of the metal complex [16].

Vanadyl salen and salophen complexes are able to catalyze numerous reactions, among them oxidative processes in which the metal reacts with peroxides to form peroxometal species for the oxidation of organic substrates [9-11]. Moreover, they are also useful as model systems for the investigation of vanadium based biochemical processes. As an example, natural vanadium-dependent enzymes, such as haloperoxidases, are essential in nature for the oxidation of halides to halogenating reagents via activation of hydrogen peroxide $[1,6]$.

The introduction of Schiff base ligands in the vanadyl coordination sphere implies a series of considerable advantages. For example, vanadyl salen complexes were found to be more stable than the commercially available acetylacetonate derivative. Furthermore, the possibility to introduce a series of different substituents on the ligand scaffold would consent to tune the electronic and steric effects in the catalytic active center. Indeed, the different conformations observed for salen and salophen vanadyl complexes appeared to influence their reactivity; thus more or less rigid structures can be chosen, in order to enhance the desired activity [9].

Electronic effects can be modulated by introducing electron donor or withdrawing groups in the phenyl ring of the salicylaldehyde reagent $[9,10,17]$; on the other hand, the shape of the vanadyl complexes depends mainly on the nature of the diamine used. In agreement with 
this, theoretical calculations showed that salophen complexes reasonably react in a planar conformation, while the salen vanadyl hydroperoxo active species is more stable in a bent structure [9].

In previous papers, the variation of the Schiff base ligands was used to investigate how the oxidation reactivity of a metal complex is influenced by the electronic density on the metal $[9,10,17-19]$. Considering the oxidation with $\mathrm{H}_{2} \mathrm{O}_{2}$ of a model compound, i.e. methyl phenyl sulfide to the corresponding sulfoxide, catalyzed by $\mathrm{V}(\mathrm{V})$ salen and salophen complexes, it was shown that electronic and steric effects of the substituents combine in an unpredictable way, so that no simple clear-cut correlation between the reactivity and the electronic character of the catalysts could be established. Moreover, specific interactions intervening upon coordination of the substrate to the metal center could affect the reactivity of the vanadyl complex, as shown for similar compounds [20]. Such results prompted to perform a systematic electrochemical characterization of differently substituted vanadyl salen complexes in diverse conditions. It was demonstrated that the $\mathrm{V}(\mathrm{IV})$ to $\mathrm{V}(\mathrm{V})$ oxidation process is affected by the nature of the ligand and by the medium $[9,17]$. In particular, the oxidation potential decreases proportionally with the electron donating character and with the number of substituents on the ligand and it decreases linearly with the ability of the solvent to coordinate the complex molecules.

Electrochemical measurements are powerful tools to investigate redox active species. However, the increasing interest in the spectrofluorimetric properties of Schiff base metal complexes makes a parallel similar systematic UV-visible analysis extremely useful for future applications. From this point of view, salophen metal complexes are even more intriguing with respect to salen derivatives, due to their aromatic structure, which controls the light absorption properties. Even if an electrochemical study of differently substituted salophen vanadyl complexes has been reported [17-19], a detailed comparison with UVvisible data is still lacking.

In this paper, an integrated and systematic UV-visible (UV/Vis), electrochemical and computational study of variously substituted salophen vanadyl complexes is presented. The comparison has been also performed with different solvents and the overall picture is critically analyzed to elucidate the electronic and structural effects produced on the vanadium center.

\section{Experimental section}

\subsection{Synthesis of the ligands}

The Schiff bases used for the synthesis of $\mathrm{V}^{\mathrm{IV}} \mathrm{O}$ complexes were prepared from commercially available starting materials by the wellknown reaction between salicylaldehyde and a diamine [12,19].

\subsection{General procedure}

Two equivalents of the appropriate salicylaldehyde were dissolved in a minimal amount of boiling methanol (generally $20 \mathrm{ml}$ ). One equivalent of $o$-phenylenediamine was added dropwise and the solutions were left to cool to ambient temperature under stirring. The orange or yellow precipitates were recovered by filtration, washed with cold methanol and further purified by crystallization from ethanol when required. The purity of the ligand precursors was established by ${ }^{1} \mathrm{H}-$ NMR spectroscopy.

\subsection{Synthesis of vanadyl complexes}

A procedure slightly different from the literature one was adopted to accomplish the preparation of the vanadyl complexes. A number of vanadium derivatives were tested as precursors, i.e. $\mathrm{VO}(\mathrm{acac})_{2}$ (acac $=$ acetylacetonate) [19], vanadyl sulfate di-hydrate [21,22], and $\mathrm{V}(\mathrm{acac})_{3}[23]$. The best results in terms of reproducibility and solubility of the complexes were obtained with $\mathrm{V}(\mathrm{acac})_{3}$.

\subsubsection{General procedure}

Each Schiff base $(0.5 \mathrm{mmol}, 158 \mathrm{mg}$ in the case of salophen) was dissolved in $100 \mathrm{~mL}$ of boiling methanol, or suspended when scarcely soluble. The equimolar amount of $\mathrm{V}(\mathrm{acac})_{3}(174 \mathrm{mg}, 0.5 \mathrm{mmol})$ was completely dissolved in the minimum volume of $\mathrm{MeOH}(10 \mathrm{ml})$ with the help of sonication and added dropwise to the former solution (or to the suspension). After an overnight stirring in a vessel at room temperature, the reaction was stopped and the precipitated solid was collected, washed with diethyl ether, and dried. No trace of Schiff base was present. Eventually unreacted $\mathrm{V}(\mathrm{acac})_{3}$ was washed off with warm acetone, obtaining $139 \mathrm{mg}$ of VOsalophen (73\% yield). The substituted complexes were synthesized using the same procedure, with the amount of each ligand and yields listed in the following. The purity of all the complexes obtained was checked by TLC and HPLC. FT-IR (nujol mull) analyses have been performed for all the complexes.

2.3.1.1. $\mathrm{V}^{\mathrm{IV}}$ Osalophen. $158 \mathrm{mg}$ of the ligand was used yielding $139 \mathrm{mg}$ of the complex (73\%). Elemental analysis calculated (\%) for $\mathrm{C}_{20} \mathrm{H}_{14} \mathrm{~N}_{2} \mathrm{O}_{3} \mathrm{~V}$. MeOH: C 61.02, H 4.39, N 6.78; found: C 60.51, H 4.21, N 6.52. IR $\left(\mathrm{cm}^{-1}\right)$ 1602 ( $\mathrm{C}=\mathrm{N}$ stretch.), 991 ( $\mathrm{V}=\mathrm{O}$ stretch.).

2.3.1.2. $V^{I V} O\left(3,3^{\prime}, 5,5^{\prime}\right.$-tetra-t-butyl $)$ salophen. $270 \mathrm{mg}$ of the ligand was used yielding $263 \mathrm{mg}$ of the complex (87\%). Elemental analysis calculated (\%) for $\mathrm{C}_{36} \mathrm{H}_{46} \mathrm{~N}_{2} \mathrm{O}_{3} \mathrm{~V} \cdot \mathrm{MeOH}$ : C 69.68, H 7.90, N 4.39; found: C 70.47, H 8.26, N 4.63.

IR $\left(\mathrm{cm}^{-1}\right) 1599$ ( $\mathrm{C}=\mathrm{N}$ stretch.), 975 ( $\mathrm{V}=\mathrm{O}$ stretch.).

2.3.1.3. $V^{I V} O\left(5,5^{\prime}\right.$-di-t-butyl $)$ salophen. $214 \mathrm{mg}$ of the ligand was used yielding $202 \mathrm{mg}$ of the complex (82\%). Elemental analysis calculated (\%) for $\mathrm{C}_{28} \mathrm{H}_{30} \mathrm{~N}_{2} \mathrm{O}_{3} \mathrm{~V} \cdot \mathrm{MeOH}$ : C 66.28, H 6.52, N 5.33; found: C 67.11, H $6.03, \mathrm{~N} 6.20$.

\subsubsection{IR $\left(\mathrm{cm}^{-1}\right) 1614$ ( $C=N$ stretch.), 983 ( $V=O$ stretch.).}

2.3.1.4.1. $V^{I V} O\left(5,5^{\prime}\right.$-dimethoxy) salophen. $188 \mathrm{mg}$ of the ligand was used yielding $164 \mathrm{mg}$ of the complex (87\%). Elemental analysis calculated (\%) for $\mathrm{C}_{22} \mathrm{H}_{18} \mathrm{~N}_{2} \mathrm{O}_{5} \mathrm{~V} \cdot \mathrm{MeOH}$ : C 58.36, H 4.68, N 5.92; found: C 57.23, $\mathrm{H} 4.31, \mathrm{~N} 6.05$.

IR $\left(\mathrm{cm}^{-1}\right) 1599$ ( $\mathrm{C}=\mathrm{N}$ stretch.), 977 ( $\mathrm{V}=\mathrm{O}$ stretch.).

2.3.1.4.2. $\mathrm{V}^{\mathrm{IV}} \mathrm{O}\left(5,5^{\prime}-\mathrm{Cl}\right)_{2}$ Salophen. $194 \mathrm{mg}$ of the ligand was used yielding $176 \mathrm{mg}$ of the complex (78\%). Elemental analysis calculated (\%) for $\mathrm{C}_{20} \mathrm{H}_{12} \mathrm{Cl}_{2} \mathrm{~N}_{2} \mathrm{O}_{3} \mathrm{~V} \cdot 2 \mathrm{MeOH}$ : C 51.38, H 3.92, N 5.45; found: C 52.10, H 3.73, N 5.24 .

IR $\left(\mathrm{cm}^{-1}\right) 1610$ ( $\mathrm{C}=\mathrm{N}$ stretch.), 971 ( $\mathrm{V}=\mathrm{O}$ stretch.).

2.3.1.4.3. $\mathrm{V}^{I V} \mathrm{O}\left(3,3^{\prime}, 5,5^{\prime}-\mathrm{Cl}\right)_{4}$ salophen. $230 \mathrm{mg}$ of the ligand was used yielding $204 \mathrm{mg}$ of the complex (78\%). Elemental analysis calculated (\%) for $\mathrm{C}_{20} \mathrm{H}_{10} \mathrm{Cl}_{4} \mathrm{~N}_{2} \mathrm{O}_{3} \mathrm{~V} \cdot \mathrm{MeOH}$ : C 47.53, H 3.47, $\mathrm{N}$ 4.82; found: C 48.11, H 3.30, N 5.01 .

IR $\left(\mathrm{cm}^{-1}\right) 1602$ ( $\mathrm{C}=\mathrm{N}$ stretch.), 991 ( $\mathrm{V}=\mathrm{O}$ stretch.).

Note: further information about the procedures followed for the synthesis of all the ligands and the complexes are reported in Refs. [9] and [10]. All the vanadyl complexes have been further characterized by ESI-MS (electrospray ionization-mass spectrometry) [10].

\subsection{UV/Vis spectroscopy}

All the complexes were characterized in THF, DMF and $\mathrm{CH}_{3} \mathrm{CN}$ (spectroscopic-grade Fluka and Sigma Aldrich). UV-visible spectra were recorded on a SHIMADZU 2450 spectrometer equipped with the UV Probe 2.34 program. The solutions of substituted VOsalophen were analyzed in concentration range of about $10^{-5}-10^{-7} \mathrm{M}$ to characterize bands below $500 \mathrm{~nm}$, and $10^{-4}-10^{-2} \mathrm{M}$ to characterize the band around $600 \mathrm{~nm}$. UV/Vis spectra are consistent with literature data $[24,25]$.

$\mathrm{V}^{\mathrm{IV}} \mathrm{O}\left(3,3^{\prime}, 5,5^{\prime}\right.$-tetra-t-butyl)salophen $\left[\lambda_{\max }, \mathrm{nm}\left(\varepsilon, \mathrm{M}^{-1} \mathrm{~cm}^{-1}\right)\right]$. In $\mathrm{CH}_{3} \mathrm{CN}: 250$ (43,300), 327 (25,900), 417 (19,400); in DMF: 327 (17,200), 419 (11,500); in THF: 329 (25,300), 421 (17,300), 646 (120). 
$\mathrm{V}^{\mathrm{IV}} \mathrm{O}\left(5,5^{\prime}\right.$-di-t-butyl)salophen $\left[\lambda_{\max }, \mathrm{nm}\left(\varepsilon, \mathrm{M}^{-1} \mathrm{~cm}^{-1}\right)\right]$. In $\mathrm{CH}_{3} \mathrm{CN}$ : 247 (41,000), 318 (22,700), 409 (15,400); in DMF: 318 (18,500), 414 $(14,500)$; in THF: 319 (19,500), $416(14,200), 622(100)$.

$\mathrm{V}^{\mathrm{IV}} \mathrm{O}\left(5,5^{\prime}\right.$-dimethoxy)salophen $\left[\lambda_{\max }, \mathrm{nm}\left(\varepsilon, \mathrm{M}^{-1} \mathrm{~cm}^{-1}\right)\right]$. In $\mathrm{CH}_{3} \mathrm{CN}$ : 243 (40,000), 289 (31,000), 300 (32,000), 340 (33,000), 434 (9000); in DMF: 300 (25,000), 337 (12,800), 351 (13,000), 442 (5900); in THF: 338 (31,000), 348 (32,000), 442 (14,800), 620 (qual.).

$\mathrm{V}^{\mathrm{IV}}$ Osalophen $\left[\lambda_{\max }, \mathrm{nm}\left(\varepsilon, \mathrm{M}^{-1} \mathrm{~cm}^{-1}\right)\right]$. In $\mathrm{CH}_{3} \mathrm{CN}: 242(40,000)$, 313 (24,000), 397 (19,000); in DMF: 315 (21,000), 401 (17,500); in THF: 314 (13,000), 405 (11,000), 615 (110).

$\mathrm{V}^{\mathrm{IV}} \mathrm{O}\left(5,5^{\prime}-\mathrm{Cl}\right)_{2}$ salophen $\left[\lambda_{\max }, \mathrm{nm}\left(\varepsilon, \mathrm{M}^{-1} \mathrm{~cm}^{-1}\right)\right]$. In $\mathrm{CH}_{3} \mathrm{CN} 270$ (68,000), 305 (13,000), 409 (11,000); in DMF: 305 (14,400), 413 $(12,000)$; in THF: 305 (14,800), 415 (12,200).

$\mathrm{V}^{\mathrm{IV}} \mathrm{O}\left(3,3^{\prime}, 5,5^{\prime}-\mathrm{Cl}\right)_{4}$ salophen $\left[\lambda_{\max }, \mathrm{nm}\left(\varepsilon, \mathrm{M}^{-1} \mathrm{~cm}^{-1}\right)\right]$. In $\mathrm{CH}_{3} \mathrm{CN}$ 249, 305, 325, 410 (not-completely dissolved); in DMF: $306(16,800)$, 326 (16,300), 415 (13,000); in THF: 312 (20,000), 328 (19,500), 422 (14,000), 612 (qual.).

\subsection{Electrochemical measurements}

Reagents and anhydrous solvents (THF, DMF, $\mathrm{CH}_{3} \mathrm{CN}$ over molecular sieves) were purchased from Sigma-Aldrich and used without further purification. Tetrabutylammonium perchlorate (TBAP), used as supporting electrolyte, was recrystallized three times from ethanol and dried under vacuum.

Electrochemical experiments were performed with a Palmsens potentiostat. A small amount of each compound was added to a solution $0.1 \mathrm{M}$ of TBAP in the dried solvent of choice. A standard calomel electrode (SCE) was used as the reference electrode, a platinum wire as the auxiliary electrode and a platinum disk (diameter $1 \mathrm{~mm}$ ) as the working electrode. A glassy carbon electrode was also tested as the working electrode. Four runs were performed at 25, 50, 100, and $200 \mathrm{mV} / \mathrm{s}$ scan rates for each compound, giving reproducible results.

All the experiments were performed in a -1.5 to $1.5 \mathrm{~V}$ versus SCE range scale in which the electrochemical peaks of $\mathrm{V}^{\mathrm{IV}} / \mathrm{V}^{\mathrm{V}}$ couple are observed in the positive window of the scan.

Two runs of differential pulse voltammetry (DPV) were performed in the range of $0-1 \mathrm{~V}$ (starting from $0 \mathrm{~V}$ and from $1 \mathrm{~V}$, respectively) for each compound in different solvents at $25 \mathrm{mV} / \mathrm{s}$ scan rate.

\subsection{Calculations}

All DFT (density functional theory) calculations were performed using Gaussian 09 revision A.02 [26]. Geometry optimizations were carried out with DFT calculations using the B3LYP hybrid functional with the $6-31 \mathrm{G}+(\mathrm{d}, \mathrm{p})$ basis set including solvent effects with the IEFPCM method $[27,28]$. UV/Vis spectra calculations were performed by timedependent (TD)-DFT using B3LYP as functional, 6-31G+(d,p) as basis set and unrestricted wavefunction.

\section{Results and discussion}

\subsection{Electrochemical measurements}

The vanadium salophen complexes investigated have different substituents in the periphery of the aromatic scaffold, as shown in Scheme 1, introduced to modify the electronic character of the vanadium atom.

In a previous work [9] the species were tested, together with similarly substituted salen vanadyl complexes, as Lewis acid catalysts in the oxidation of methyl phenyl sulfide. In principle, the introduction of electron withdrawing substituents in the ligands should increase the electrophilicity of the metal, thus enhancing its Lewis acidity. Practically, no simple correlation could be established between substituent electronic effects and reaction outcome. Computational calculations helped to understand the fundamental contribution of steric effects:

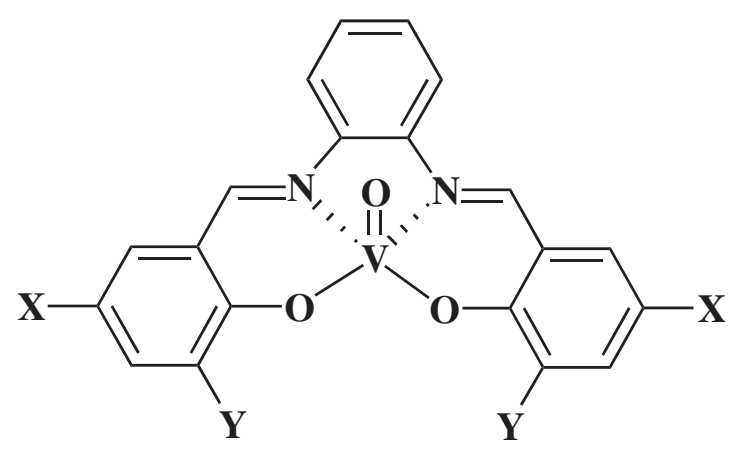

$\begin{array}{ll}\mathbf{X}={ }^{t} \mathbf{B u} & \mathbf{Y}={ }^{t} \mathbf{B u} \\ \mathbf{X}={ }^{t} \mathbf{B u} & \mathbf{Y}=\mathbf{H} \\ \mathbf{X}=\mathbf{O M e} & \mathbf{Y}=\mathbf{H} \\ \mathbf{X}=\mathbf{H} & \mathbf{Y}=\mathbf{H} \\ \mathbf{X}=\mathbf{C l} & \mathbf{Y}=\mathbf{H} \\ \mathbf{X}=\mathbf{C l} & \mathbf{Y}=\mathbf{C l}\end{array}$

Scheme 1. Structure of the investigated VOsalophen derivatives.

vanadium complexes are likely forced to assume a bent conformation upon formation of the oxidohydroperoxido complex, which is the active oxidant species. This particular arrangement may result in an unpredictable combination of steric and electronic effects of the substituents. Analysing these complexes, it has been noted $[17,29]$ that the oxidation potential of the $\mathrm{V}^{\mathrm{IV}} / \mathrm{V}^{\mathrm{V}}$ species could be a better parameter to investigate the substitution effects, so that an electrochemical characterization of substituted vanadyl complexes represents one of the best ways to assess the overall electronic effects on the metal ion. Earlier, a systematic analysis of the oxidation potential of VOsalen has been performed with cyclic voltammetry in different solvents [17]. In the present paper the analysis has been extended to VOsalophen derivatives in order to elucidate how the oxidation potential is influenced by substituents on the salophen macrocycle or by solvents.

Compounds of Scheme 1 have been studied with cyclic voltammetry and DPV in DMF, $\mathrm{CH}_{3} \mathrm{CN}$ and THF. The three solvents were chosen for

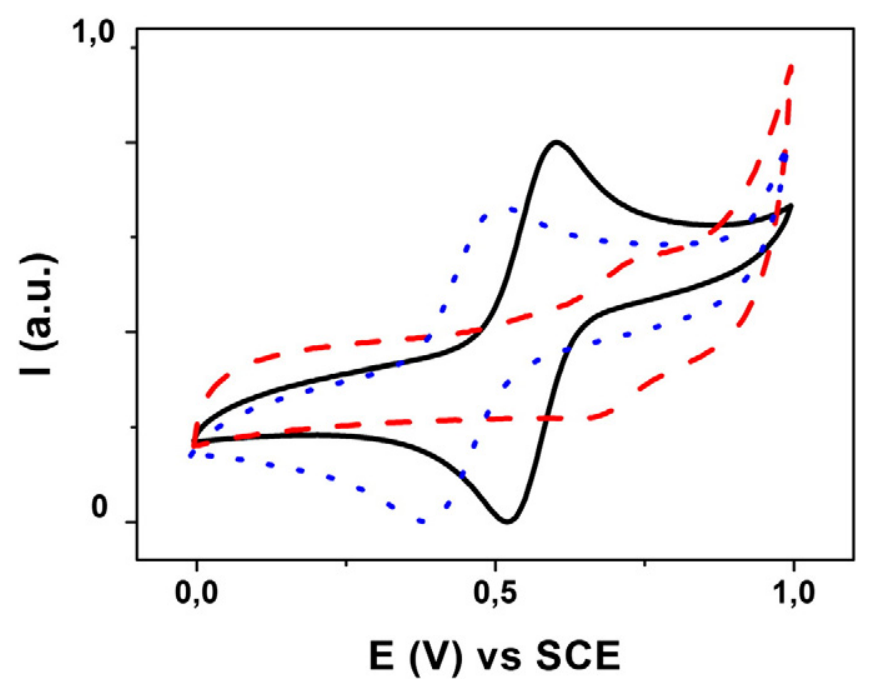

Fig. 1. $\mathrm{CV}(100 \mathrm{mV} / \mathrm{s})$ of $\mathrm{VO}$ (tetra- $\left.{ }^{t} \mathrm{Bu}\right)$ salophen (blue dotted line), VOsalophen (black solid line) and $\mathrm{VO}$ (tetra- $\mathrm{Cl}$ ) salophen (red dashed line) in $\mathrm{CH}_{3} \mathrm{CN}$. 


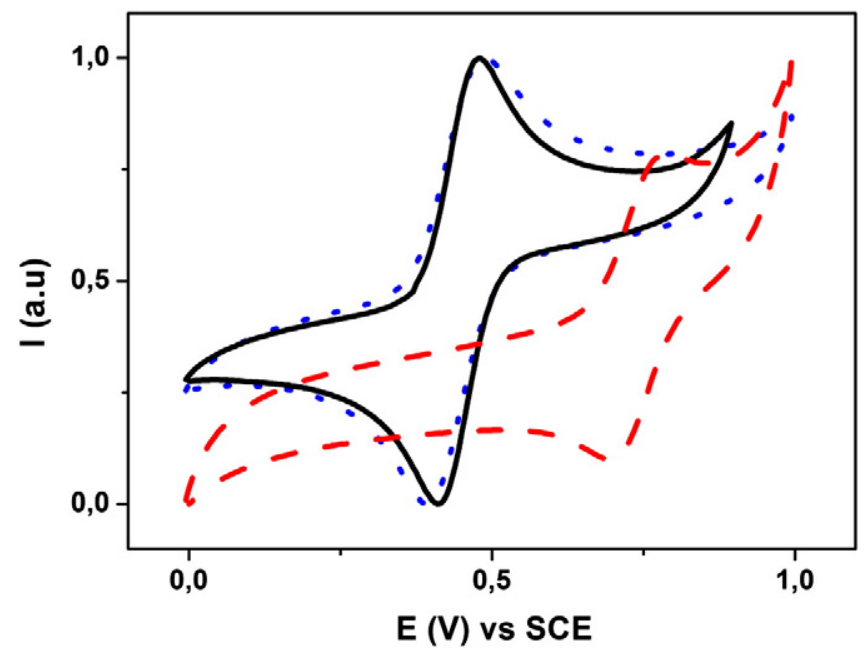

Fig. 2. $\mathrm{CV}(100 \mathrm{mV} / \mathrm{s})$ of $\mathrm{VO}\left(\right.$ tetra- $\left.{ }^{t} \mathrm{Bu}\right)$ salophen (blue dotted line), VOsalophen (black solid line) and $\mathrm{VO}$ (tetra-Cl)salophen (red dashed line) in DMF.

the significant variations of their physical properties and for their frequent use in catalytic reactions. The curves obtained show reversible single oxidation $\mathrm{V}^{\mathrm{IV}}$ to $\mathrm{V}^{\mathrm{V}}$ for all the solvents used, with the cathodic and anodic peaks found at defined and reproducible potential values (Figs. 1-3). The cyclic voltammogram of unsubstituted VOsalophen is shown together with those of tetra- $\mathrm{Cl}$ and tetra- ${ }^{t} \mathrm{Bu}$ derivatives, giving an idea of the maximum range of potential difference occurring among all the studied complexes. The oxidation potential values obtained for each compound in the different solvents are reported in Table 1 and are in agreement with the results of the DPV (Fig. 5). DPV setup involves a lower scan rate and a different potential variation during the experiment, and for these reasons, this technique allows a better resolution and higher sensitivity in particular for low soluble and/or slow rate electrochemical processes. As expected, this technique proved to be particularly useful to clearly identify the oxidation potential in case of scarcely soluble complexes (i.e., tetrachloro- and dichlorosalophen derivatives in $\mathrm{CH}_{3} \mathrm{CN}$ ). The anodic and cathodic peak potential separation values $(\Delta \mathrm{E})$ are always in the range between 70 and $200 \mathrm{mV}$,

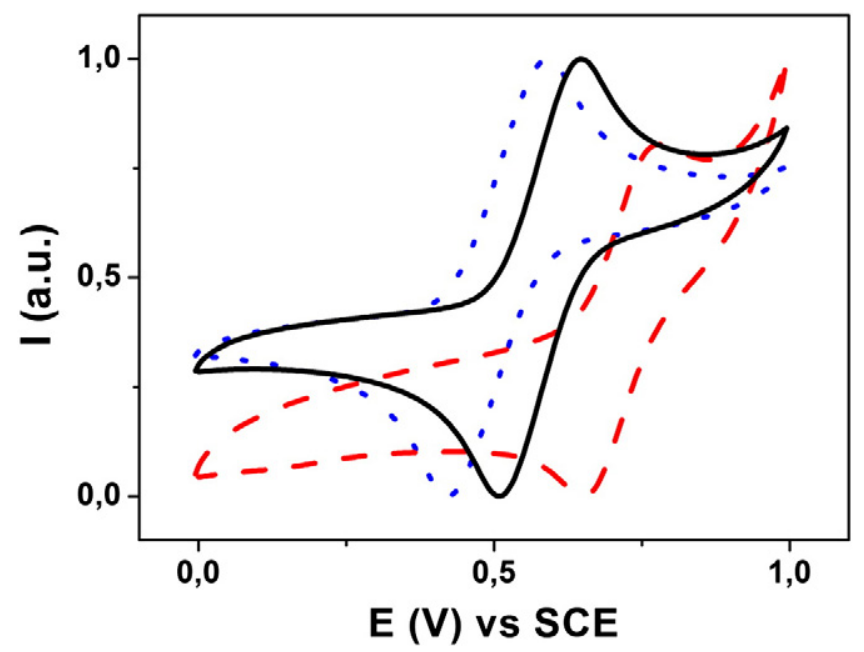

Fig. 3. $\mathrm{CV}(100 \mathrm{mV} / \mathrm{s})$ of $\mathrm{VO}\left(\right.$ tetra- $\left.{ }^{\mathrm{t}} \mathrm{Bu}\right)$ salophen (blue dotted line), VOsalophen (black solid line) and $\mathrm{VO}$ (tetra- $\mathrm{Cl}$ ) salophen (red dashed line) in THF.
Table 1

Redox potential for the $\mathrm{V}^{\mathrm{IV}} / \mathrm{V}^{\mathrm{V}}$ oxidation process of oxido- $\mathrm{V}(\mathrm{IV})$ salophen complexes, in different solvents at $100 \mathrm{mV} / \mathrm{s}$, using TBAP $0.1 \mathrm{M}$.

\begin{tabular}{|c|c|c|c|c|c|}
\hline & & Solvent & $\begin{array}{l}E_{1 / 2} \text { vs SCE, } V \\
\left(V^{I V} / V^{V}\right)\end{array}$ & $\Delta \mathrm{E}, \mathrm{V}$ & $\Sigma \sigma$ \\
\hline$X$ & $\mathrm{Y}$ & & & & \\
\hline \multirow[t]{3}{*}{${ }^{t} \mathrm{Bu}$} & ${ }^{t} \mathrm{Bu}$ & DMF & 0.440 & 0.100 & \\
\hline & & $\mathrm{CH}_{3} \mathrm{CN}$ & 0.445 & 0.130 & -0.788 \\
\hline & & THF & 0.505 & 0.170 & \\
\hline \multirow[t]{3}{*}{ OMe } & $\mathrm{H}$ & DMF & 0.495 & 0.080 & \\
\hline & & $\mathrm{CH}_{3} \mathrm{CN}$ & 0.520 & 0.090 & -0.394 \\
\hline & & THF & 0.558 & 0.280 & \\
\hline \multirow[t]{3}{*}{${ }^{t} \mathrm{Bu}$} & $\mathrm{H}$ & DMF & 0.470 & 0.080 & \\
\hline & & $\mathrm{CH}_{3} \mathrm{CN}$ & 0.505 & 0.090 & -0.536 \\
\hline & & THF & 0.548 & 0.200 & \\
\hline \multirow[t]{3}{*}{$\mathrm{H}$} & $\mathrm{H}$ & DMF & 0.460 & 0.070 & \\
\hline & & $\mathrm{CH}_{3} \mathrm{CN}$ & 0.560 & 0.080 & 0 \\
\hline & & THF & 0.578 & 0.135 & \\
\hline \multirow[t]{3}{*}{$\mathrm{Cl}$} & $\mathrm{H}$ & DMF & 0.545 & 0.090 & \\
\hline & & $\mathrm{CH}_{3} \mathrm{CN}$ & 0.613 & 0.060 & 0.454 \\
\hline & & THF & 0.638 & 0.165 & \\
\hline \multirow[t]{3}{*}{$\mathrm{Cl}$} & $\mathrm{Cl}$ & DMF & 0.740 & 0.090 & \\
\hline & & $\mathrm{CH}_{3} \mathrm{CN}$ & 0.708 & 0.080 & 0.908 \\
\hline & & THF & 0.713 & 0.125 & \\
\hline
\end{tabular}

thus indicating the occurrence of a quasi-reversible process in the experimental conditions utilized.

$\Sigma \sigma$ values have been used as parameters to investigate the electronic effect of the substituents on the vanadium [30]. The considered series range from a -0.8 value, for the ligand carrying four highly electron donating $t$-butyl groups, to +1 , for the ligand bearing the four strong electron withdrawing chlorine atoms. The type and number of substituent groups have been selected in order to embrace a large variation of the electronic character of the metal atom.

The trend of the redox potential relative to $\Sigma \sigma$ values is shown in Fig. 6. Oxidation potential value for the $\mathrm{V}^{\mathrm{IV}} / \mathrm{V}^{\mathrm{V}}$ process increases proportionally with the electron withdrawing character and with the number of substituents on the ligand, thus confirming that the introduction of electron donating groups can decrease the Lewis acidity of the metal, which is the reactive site. This trend was confirmed in the three solvents

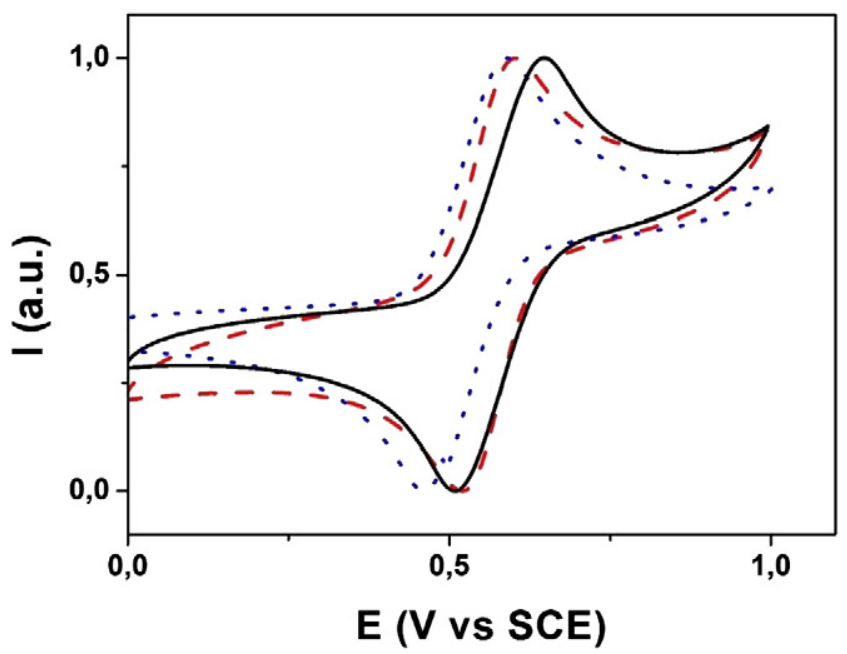

Fig. 4. $\mathrm{CV}(100 \mathrm{mV} / \mathrm{s})$ of unsubstituted VOsalophen in DMF (blue dotted line), $\mathrm{CH}_{3} \mathrm{CN}$ (red dashed line) and THF (black solid line). 

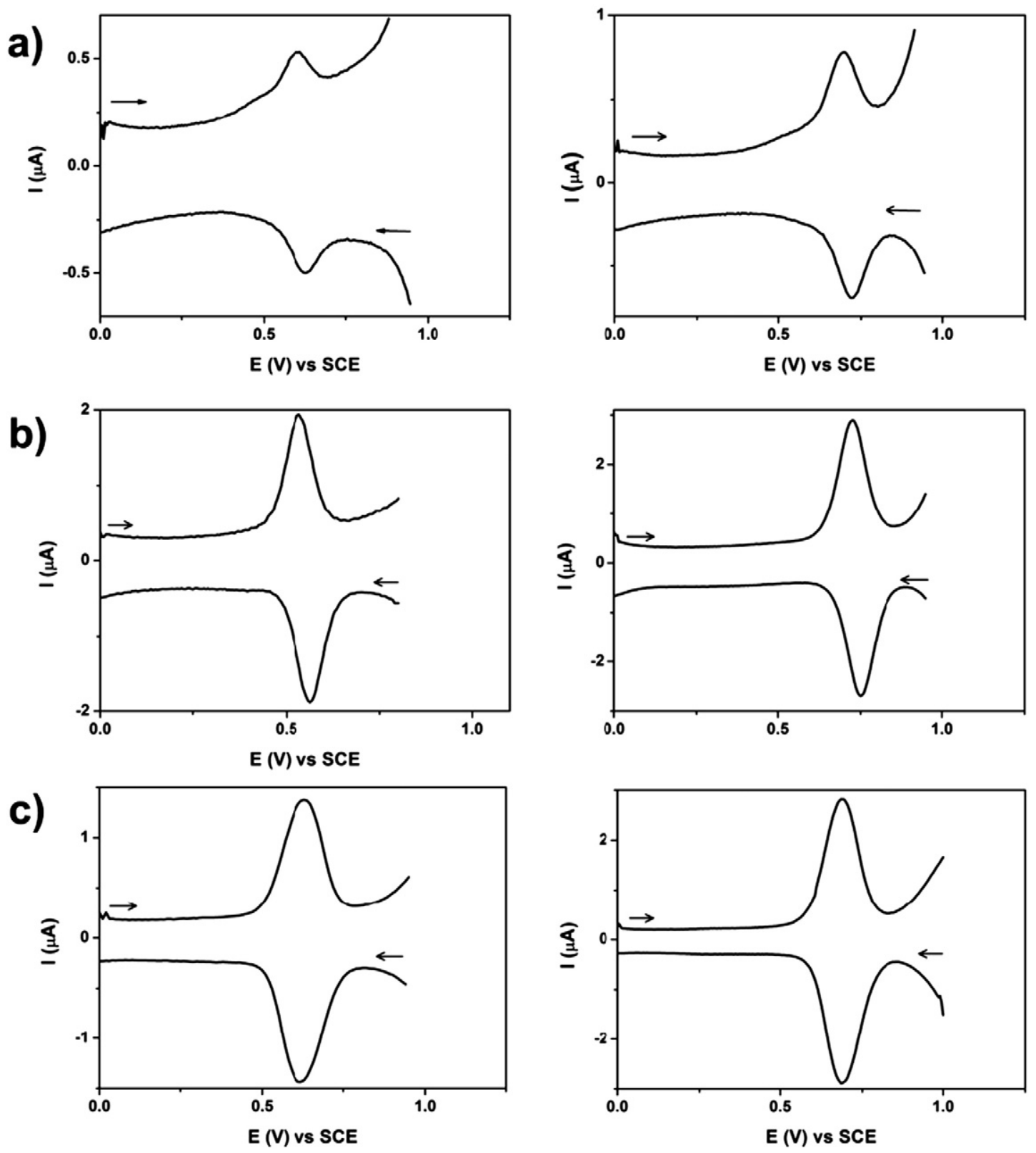

Fig. 5. $\mathrm{DPV}(25 \mathrm{mV} / \mathrm{s})$ of $\mathrm{VO}(\mathrm{di}-\mathrm{Cl})$ salophen (left) and $\mathrm{VO}$ (tetra-Cl)salophen (right) with TBAP $0,1 \mathrm{M}$ in $\mathrm{CH}_{3} \mathrm{CN}(\mathrm{a})$, DMF (b) and THF (c).

considered. However, there are evident deviations from a good correlation, especially in DMF, the solvent exhibiting the highest coordination ability; a characteristic that may strongly influence the electron density around the metal as well as the geometry of the resulting complex.

The comparison of oxidation potentials of vanadyl salophen compounds in the three solvents, as demonstrated by the cyclic voltammograms of VOsalophen in Fig. 4, shows that a peaks shift occurs moving from DMF to $\mathrm{CH}_{3} \mathrm{CN}$ or THF. The observed trend, for all the analyzed compounds (with the only exception of $\mathrm{VO}$ (tetra-Cl)salophen), is an increase of the $\mathrm{E}_{1 / 2}$ values going from DMF to $\mathrm{CH}_{3} \mathrm{CN}$ and then to THF. At first glance, an effect of the solvent polarity on the oxidation potential can be invoked, even though attempts to correlate it with the solvent dielectric constant failed. A further tentative was made correlating the oxidation potentials values with solvent donor number (DN) a parameter that represents the ability of a solvent to coordinate to solute molecules, i.e. the solvent Lewis basicity. At odd with the similar VOsalen complex, which showed a good correlation of $E_{1 / 2}$ with the solvents DN [17], in the present study, using the same parameters, no linear correlation could be obtained whatsoever. Therefore, it appears that the effect exhibited by the salophen scaffold on vanadium metal is too complicated to allow a simple single parameter correlation, as discussed also in a recent paper [31]. The non-significant variation of oxidation potential observed there is probably due to the naphthalene moiety present in the salophen complex. To note, in order to attempt a multiparameter correlation, investigation of a larger number of solvents would be required.

While a mathematic correlation is not derivable, it was evident that both donor number and dielectric constant influence the oxidation potential. DN is related to the attitude to coordinate the metal ion: higher values indicating a better coordination ability of the solvent. Therefore, in the presence of a better donating solvent the metal experiences a higher electron density that allows an easier oxidation of the vanadium ion. In addition, solvent polarity is also related to the capability to stabilize charged species in solution. During the oxidation process the $\mathrm{V}^{\mathrm{IV}}$ species goes to $\mathrm{V}^{\mathrm{V}}$ that is cationic $(+1)$. Reasonably, raising the solvent dielectric constant implies a stability gain of the salophen $V^{\mathrm{V}} \mathrm{O}$ 


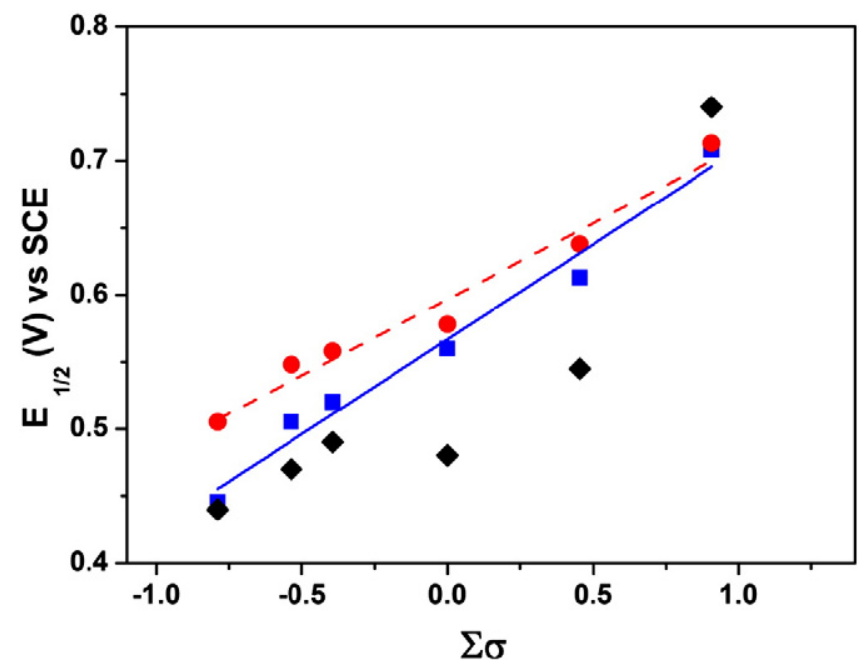

Fig. 6. $\mathrm{V}^{\mathrm{IV}} / \mathrm{V}^{\mathrm{V}}$ oxidation potential for the different VOsalophen derivatives as a function of the substituent $\Sigma \sigma$ values: THF (red circles, dashed line), $\mathrm{CH}_{3} \mathrm{CN}$ (blue squares, solid line) and DMF (black diamonds).

product that, being a charged species, may be better coordinated by the solvent molecules; hence, again the metal atom can be more easily oxidized.

\subsection{UV/Vis spectroscopy study}

The electronic properties of metal complexes are generally greatly susceptible to the coordination environment. A minimal variation in the surroundings of the metal atom can be, for example, easily examined by spectroscopy. To rationalise how different substituents in the periphery of the aromatic salophen scaffold modify the electronic character of vanadium, UV/Vis absorption spectroscopy analysis of the compounds listed in Scheme 1, in $\mathrm{CH}_{3} \mathrm{CN}, \mathrm{DMF}$ and THF, has been performed.

The VOsalophen spectrum is shown in Fig. 7 (left). The electronic spectra of $\mathrm{VO}(\mathrm{X}, \mathrm{Y})$ salophen generally consist of three absorption bands in the ranges of $240-270 \mathrm{~nm}, 300-350 \mathrm{~nm}$ and $395-450 \mathrm{~nm}$ (the di-OMe complex shows a shifted band at lower wavelength). Moreover, another absorption can be found at about $600 \mathrm{~nm}$ that cannot be easily characterized, due to its low molar extinction coefficient (80$150 \mathrm{M}^{-1} \mathrm{~cm}^{-1}$ ). This last band is shown more in detail in Fig. 7 (right) for different $\mathrm{VO}(\mathrm{X}, \mathrm{Y})$ salophen compounds in THF, in concentrations appropriate to give similar absorbances. To this respect the bands are

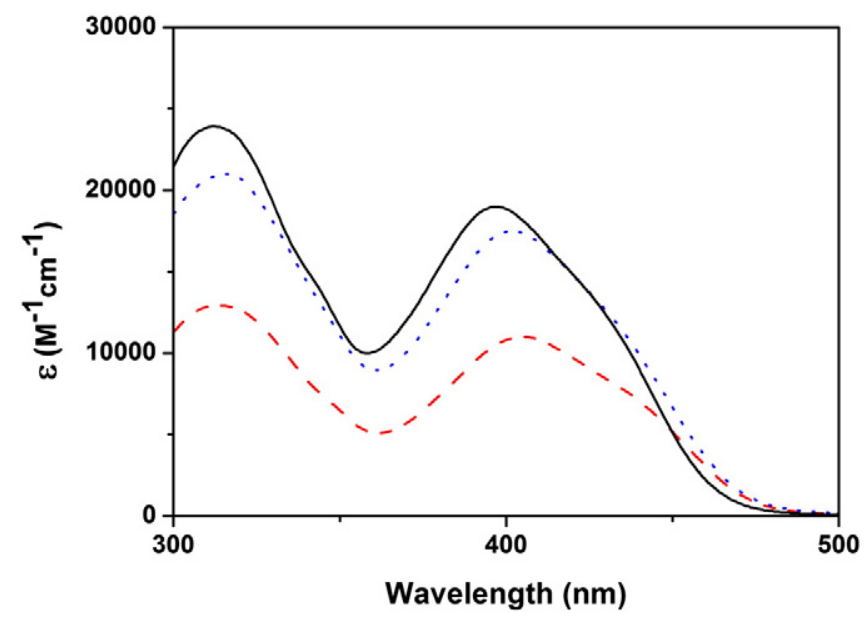

Fig. 8. UV/Vis Spectrum of VOsalophen in $\mathrm{CH}_{3} \mathrm{CN}$ (black solid line), DMF (blue dotted line) and THF (red dashed line).

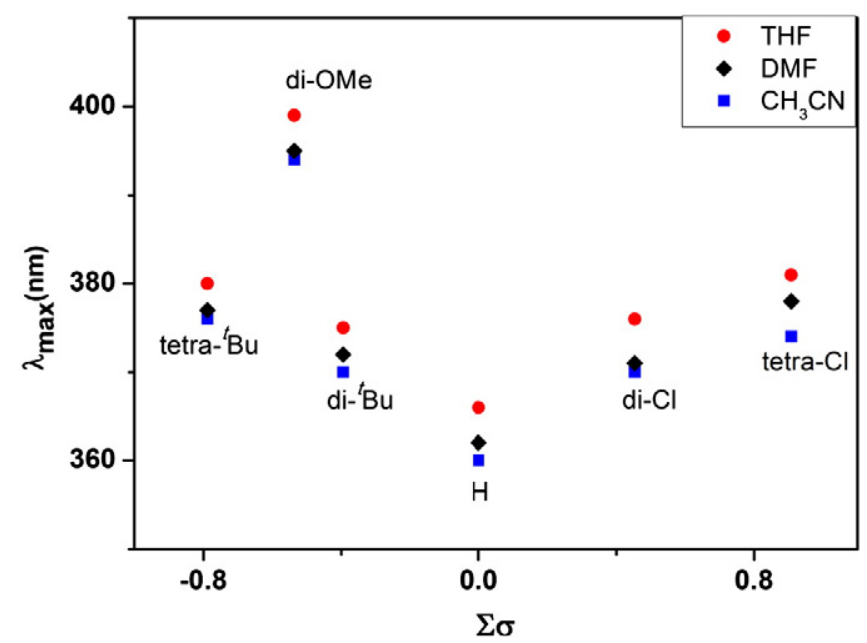

Fig. 9. Correlation attempt for the absorption bands maxima in different solvents

reported and discussed in the following only when reliable $\lambda_{\max }$ and $\varepsilon$ values could be obtained.

The absorption band around $400 \mathrm{~nm}$ is characteristic of all the spectra and $\lambda_{\max }$ values are influenced by the substituent(s) on the salophen
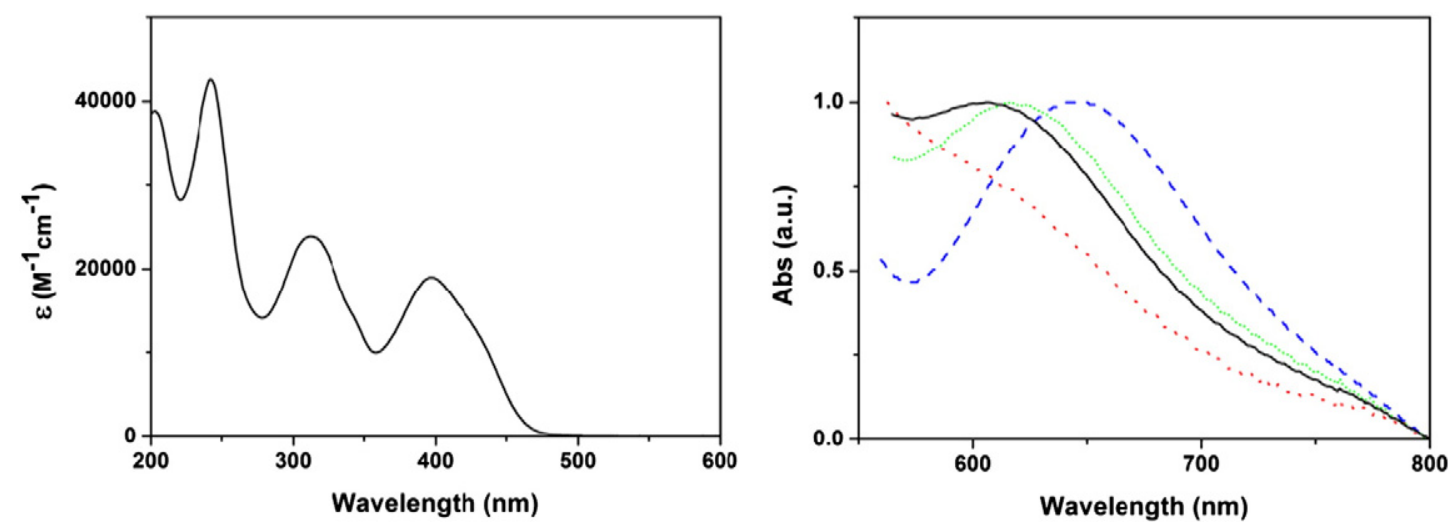

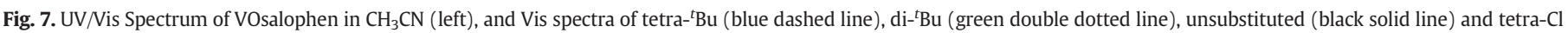
(red dotted line) VOsalophen complexes in THF. 


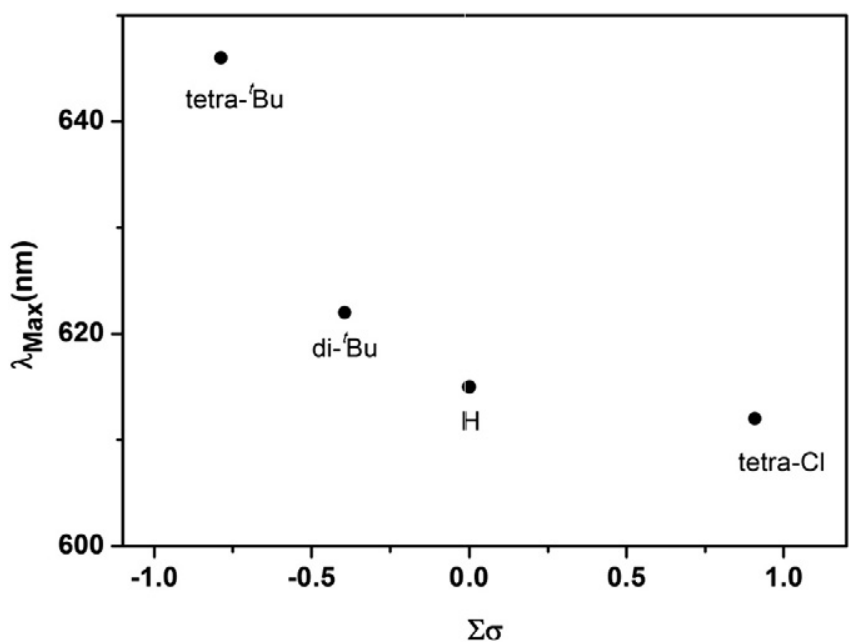

Fig. 10. Variation of the $\lambda_{\max }$ of the $600 \mathrm{~nm}$ absorption with $\Sigma \sigma$ in THF.

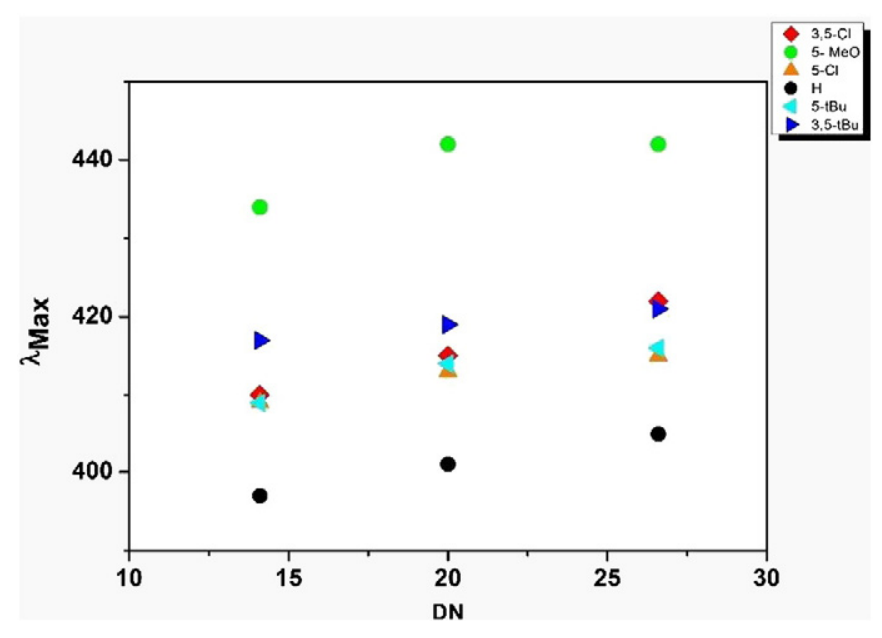

Fig. 11. Correlation between substituted VOsalophen $\lambda_{\max }(\mathrm{nm})$ and solvent DNs.

macrocycle. An effort to correlate electronic variations in the periphery of the aromatic scaffold with the shift of the bands has been endeavored using the sum of Hammett parameter $\Sigma \sigma[30]$, also reported in Table 1. As it is clearly visible in Fig. 9, there is no linear correlation among
Table 2

Results of TD-DFT/B3LYP/6-31G+ (d,p) calculations for oxido-V(IV) salophen complexes.

\begin{tabular}{|c|c|c|c|c|}
\hline & & $\lambda_{\text {exp }}, \mathrm{nm}$ & $\lambda_{\text {calc }}, \mathrm{nm}$ & M.O.s involved ${ }^{\mathrm{a}}$ \\
\hline $\mathrm{X}$ & $\mathrm{Y}$ & & & \\
\hline \multirow[t]{2}{*}{${ }^{t} \mathrm{Bu}$} & ${ }^{t} \mathrm{Bu}$ & 417 & 429 & $\mathrm{SOMO} \rightarrow($ LUMO +3$)$ \\
\hline & & 646 & 660 & $\mathrm{SOMO} \rightarrow$ LUMO \\
\hline \multirow[t]{2}{*}{ OMe } & $\mathrm{H}$ & 474 & 473 & $($ HOMO-1) $\rightarrow($ LUMO +1$)$ \\
\hline & & $610-620$ & 619 & SOMO $\rightarrow$ LUMO \\
\hline \multirow[t]{2}{*}{${ }^{t} \mathrm{Bu}$} & $\mathrm{H}$ & 409 & 407 & $($ HOMO-1) $\rightarrow($ LUMO + 1) \\
\hline & & 622 & 619 & SOMO $\rightarrow$ LUMO \\
\hline \multirow[t]{2}{*}{$\mathrm{H}$} & $\mathrm{H}$ & 397 & 397 & $\mathrm{SOMO} \rightarrow($ LUMO +3$)$ \\
\hline & & 615 & 620 & $\mathrm{SOMO} \rightarrow$ LUMO \\
\hline \multirow[t]{2}{*}{$\mathrm{Cl}$} & $\mathrm{H}$ & 409 & 408 & $(\mathrm{HOMO}-1) \rightarrow(\mathrm{LUMO}+1)$ \\
\hline & & $610-620$ & 613 & $\mathrm{SOMO} \rightarrow$ LUMO \\
\hline \multirow[t]{2}{*}{$\mathrm{Cl}$} & $\mathrm{Cl}$ & 410 & 420 & $\mathrm{SOMO} \rightarrow($ LUMO +2$)$ \\
\hline & & 612 & 610 & SOMO $\rightarrow$ LUMO \\
\hline
\end{tabular}

${ }^{\mathrm{a}} \mathrm{HOMO}=$ highest occupied molecular orbital, SOMO = singly occupied molecular orbital, and LUMO = lowest unoccupied molecular orbital.

values, even though a trend appears to be the same for all solvents considered.

In order to analyze the absorption spectra, together with the substituent electronic effects, which play indeed a significant role, also distortion of the skeleton, induced by the number and dimensions of substituents, should be taken into account [9].

The $600 \mathrm{~nm}$ band, due to its low molar extinction, appears to be related to transition involving metal orbitals. The broadness of such band hampered the assignment of the maxima wavelengths (Fig. 7) and the scarce solubility of some compounds (i.e. $\mathrm{VO}$ (tetra- $\mathrm{Cl}$ ) and $\mathrm{VO}(\mathrm{di}-\mathrm{Cl})$ salophen in acetonitrile) prevented to reach the necessary concentration range $\left(10^{-2}-10^{-3} \mathrm{M}\right)$. Therefore, the corresponding $\lambda_{\max }$ and $\varepsilon$ values in $\mathrm{CH}_{3} \mathrm{CN}$ and DMF are not reported. On the other hand, Fig. 10 shows the behavior of the maxima absorption for the band at $600 \mathrm{~nm}$ in THF as a function of $\Sigma \sigma$ values. In this case, the electronic withdrawing character of the substituent appears to determine a blue shift of $\lambda_{\max }$.

A theoretical approach has been considered in order to better understand such behavior.

In principle, it is possible to theoretically investigate the influence of solvent on electronic transitions. As shown in Figs. 8 and 9, the maximum wavelength and the molar extinction coefficient $(\varepsilon)$ vary, showing a bathochromic shift for the band at $400 \mathrm{~nm}$ going from $\mathrm{CH}_{3} \mathrm{CN}$ to DMF and to THF. This trend results clear for all the compounds, despite shift
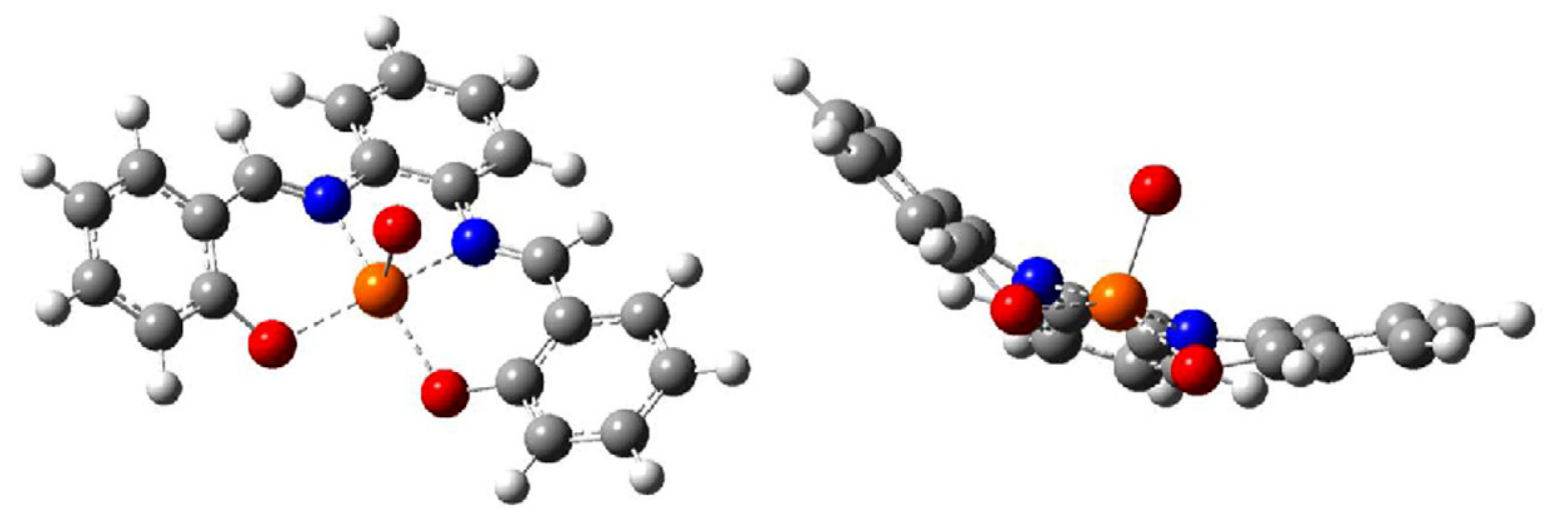

$\mathrm{V}=$ orange, $\mathrm{O}=$ red, $\mathrm{N}=$ blue

Fig. 12. VOsalophen optimized structure top and side view (DFT/B3LYP/6-31G+(d,p)). 
values are generally lower than $5 \mathrm{~nm}$. It is possible to relate the shift to the donor number (Fig. 11), confirming that this parameter influences the electronic density of the complexes (vanadium and ligand).
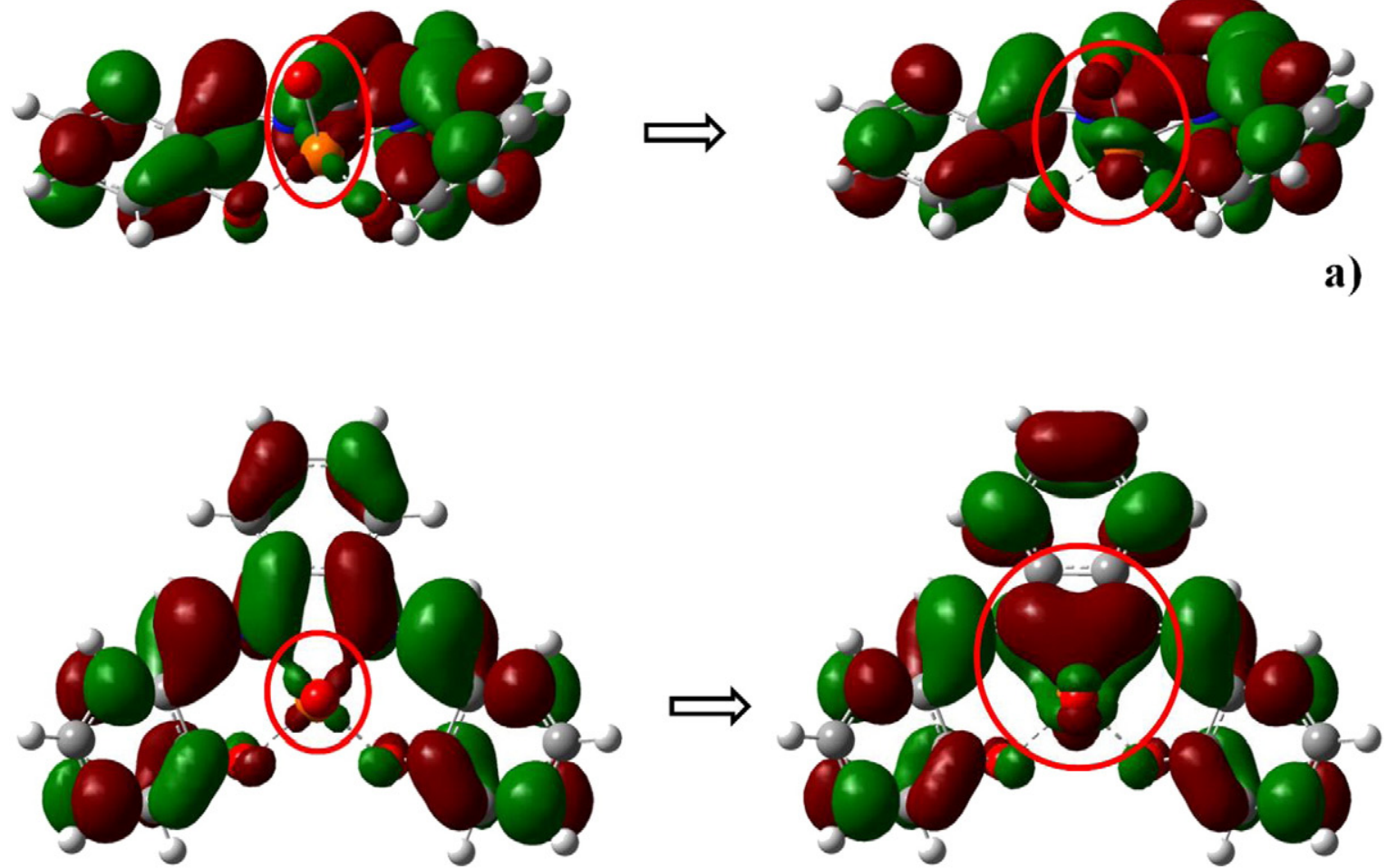

b)
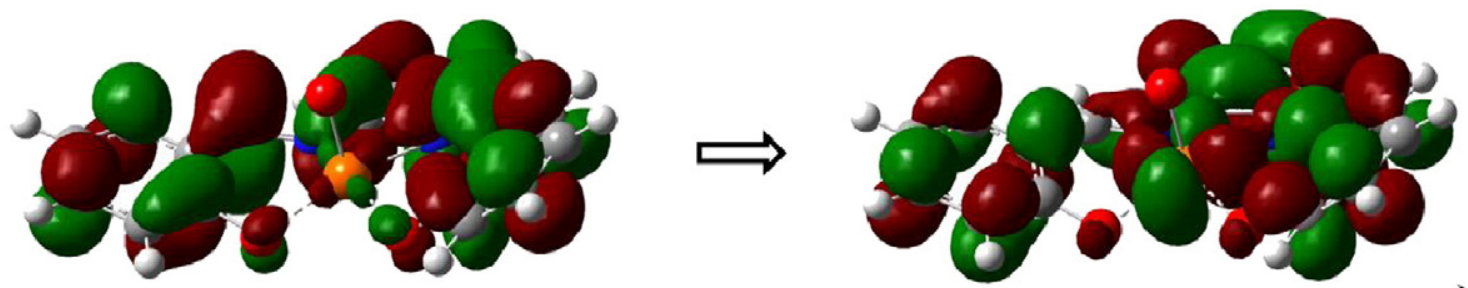

c)
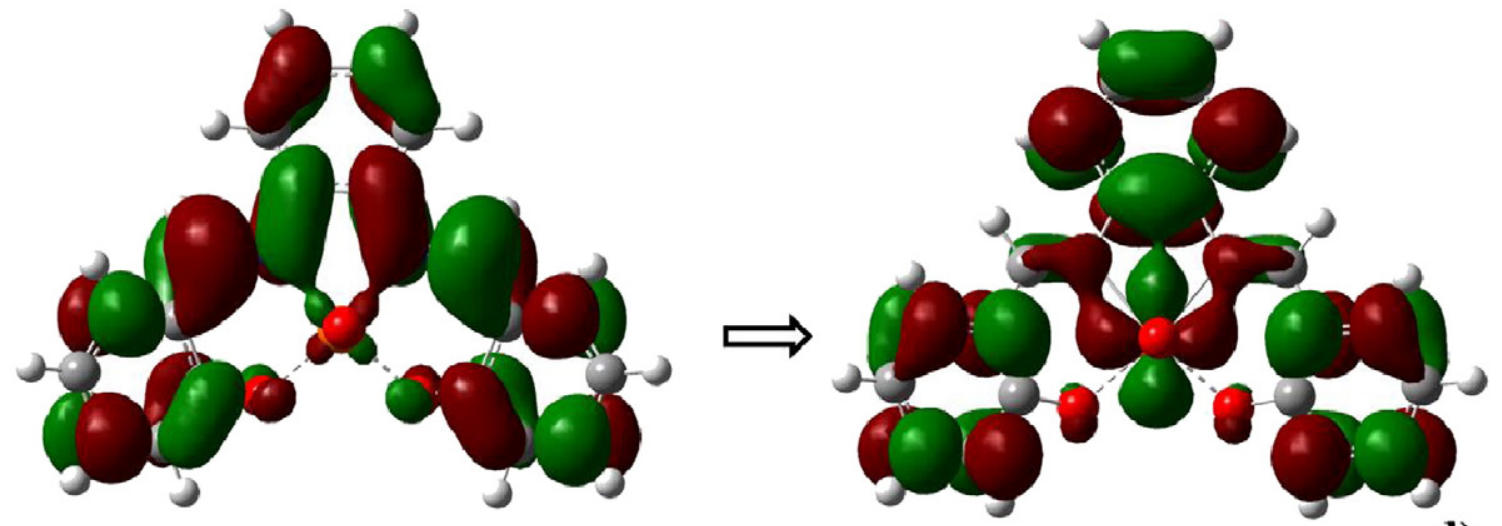

d)

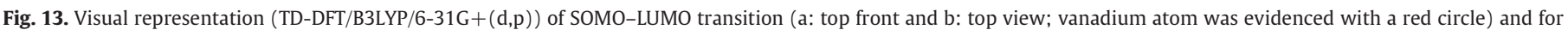
SOMO-(LUMO + 3) transition (c: top front and d: top view) for VOSalophen. 


\subsection{Theoretical calculations}

In order to deeply investigate the overall electronic effects on these complexes, density functional theory (DFT) calculations using B3LYP as functional were performed. Recent studies validate this method for predicting several molecular properties of transition metal (TM) containing systems [32,33]. The performance of LANLD2Z and 6$31+\mathrm{G}(\mathrm{d}, \mathrm{p})$ as basis sets was investigated. Both of these basis sets have been widely used along with density functional methods for computational studies of TM-containing systems [34].

Starting from the optimization of the VOsalophen structure (Fig. 12), the arrangement was validated by comparison with experimental data [21]. Then, a time depending density functional theory calculation (TD-DFT) was performed in vacuum to investigate the molecular orbitals involved in electronic transitions. Calculations were set up with both basis set (LANL2DZ and $6-31 \mathrm{G}+(\mathrm{d}, \mathrm{p})$ ) and unrestricted wavefunction. The next step was to include the solvent effects with IEFPCM method. Acetonitrile was chosen for its wider range of spectral window. A comparison between the results determines the better accuracy of the $6-31 \mathrm{G}+(\mathrm{d}, \mathrm{p})$ basis set in terms of experimental-calculation result agreement. The same approach was followed for all the substituted $\mathrm{V}^{\mathrm{IV}} \mathrm{O}$ and $\mathrm{V}^{\mathrm{V}} \mathrm{O}$ salophen complexes. TD-DFT calculation results are reported in Table 2. SOMO stands for highest singly occupied molecular orbital, HOMO-1 for highest fully occupied molecular orbital immediately below, and LUMO for lowest unoccupied molecular orbital.

Only maxima wavelengths of bands, which were more susceptible to substituent electronic effect (see paragraph 3.2), are reported. A visual representation of the molecular orbitals involved in electronic transition for the VOsalophen is shown in Figs. 13 and 14. Theoretical calculations disclose that electronic density moves from ligand to metal for both bands. Further, and even more interesting, calculated absorption maxima wavelengths are generally very close to experimental values.

It is possible to compare SOMO energies for all the VOsalophen (Table 3). It is remarkable that values are correlated with substituent electronic effects: the stability of SOMOs orbital increases proportionally with the electron withdrawing character of the ligand. This can be easily combined with evidence from UV/Vis spectroscopy study and electrochemical measurements to "shed new light" on the electronic behavior of this class of compounds. First, it is possible to state that the electronic character of the complexed vanadium atom is related to
Table 3

Results of calculations DFT/B3LYP/6-31G $+(d, p)$ calculations for oxido-V(IV) salophen complexes.

\begin{tabular}{|c|c|c|c|c|}
\hline & & $\begin{array}{l}\mathrm{V}^{\mathrm{IV}} \text { O SOMO Energy, a.u. } \\
\text { (eV, relative to the } \\
\text { unsubstituted complex) }\end{array}$ & $\begin{array}{l}\mathrm{V}^{\mathrm{IV}} \mathrm{O} \\
(\mathrm{SOMO} \rightarrow \mathrm{HOMO}-1) \\
\text { Energy gap, eV }\end{array}$ & $\Sigma \sigma$ \\
\hline $\mathrm{X}$ & $\mathrm{Y}$ & & & \\
\hline${ }^{t} \mathrm{Bu}$ & ${ }^{t} \mathrm{Bu}$ & $-0.21817(0.278)$ & 0.0125 & -0.788 \\
\hline OMe & $\mathrm{H}$ & $-0.22387(0.190)$ & 0.0402 & -0.536 \\
\hline${ }^{t} \mathrm{Bu}$ & $\mathrm{H}$ & $-0.22194(0.180)$ & 0.0446 & -0.394 \\
\hline $\mathrm{H}$ & $\mathrm{H}$ & $-0.22839(0)$ & 0.0604 & 0 \\
\hline $\mathrm{Cl}$ & $\mathrm{H}$ & $-0.23008(-0.050)$ & 0.0830 & 0.454 \\
\hline $\mathrm{Cl}$ & $\mathrm{Cl}$ & $-0.23543(-0.192)$ & 0.0703 & 0.908 \\
\hline
\end{tabular}

a a.u. = arbitrary units (Hartrees).

the electronic effects of substituents in the periphery of the aromatic scaffold. As suggested by UV/Vis spectra and calculation results, increasing the donating character of substituents leads to a decrease of the SOMO/LUMO gap. This red-shifted absorption is reasonably related to an increase of electronic density on the ligand, which leads to an overall enhanced $\pi$-delocalization.

The $\mathrm{V}^{\mathrm{IV}} / \mathrm{V}^{\mathrm{V}} \mathrm{O}$ salophen oxidation process was investigated. It is worth noting that calculations predict a decrease of the conformational distortion of the aromatic moieties moving from $\mathrm{V}(\mathrm{IV})$ to $\mathrm{V}(\mathrm{V})$ complex (Fig. 14). Probably, removal of one electron from the vanadium (SOMO complex) reduces the size of the metal allowing the oxygen atoms of the ligands to come closer to the vanadium and therefore $\mathrm{V}(\mathrm{V})$ attracts the negative ligand strongly; these effects result in the new geometry of the complex.

In an attempt to rationalize how oxidation potential values are influenced by substituents, energy differences between SOMO and HOMO-1 for all the VOSalophen have been evaluated (Table 3). The experimental trend (with the only exception of $\mathrm{VO}($ tetra- $\mathrm{Cl}$ ) salophen) appears to be confirmed (Fig. 15), despite these values do not consider the conformational distortion of the structure occurring during the oxidation. The gap increases proportionally to the strengthening of substituent withdrawing effect. This behavior could be reasonably ascribed to the relative stability of SOMOs: the higher the energy, the easier it is to donate electron.
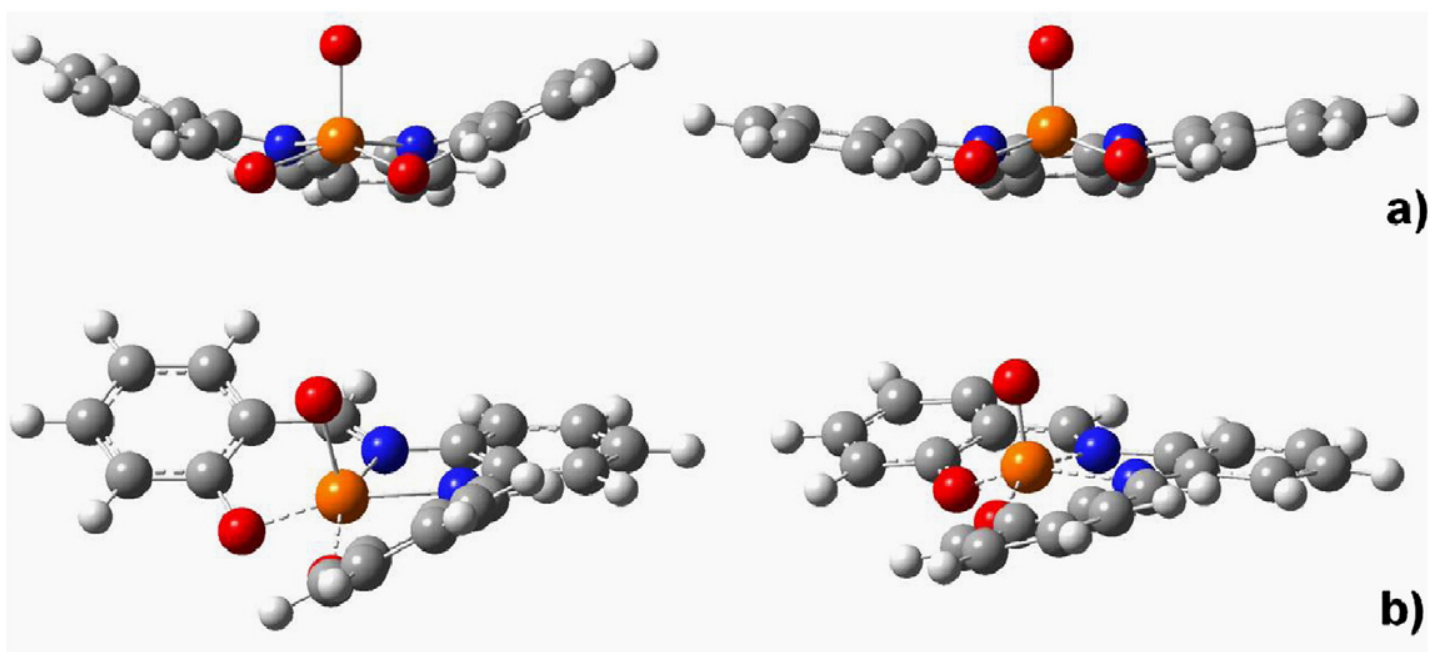

$\mathrm{V}=$ orange, $\mathrm{O}=$ red, $\mathrm{N}=$ blue

Fig. 14. Comparison between $\mathrm{V}^{\mathrm{IV}} \mathrm{O}$ (left) and $\mathrm{V}^{\mathrm{V} O}$ (right) salophen optimized geometries (a: front and b: side view) (DFT/B3LYP/6-31G+(d,p)). 


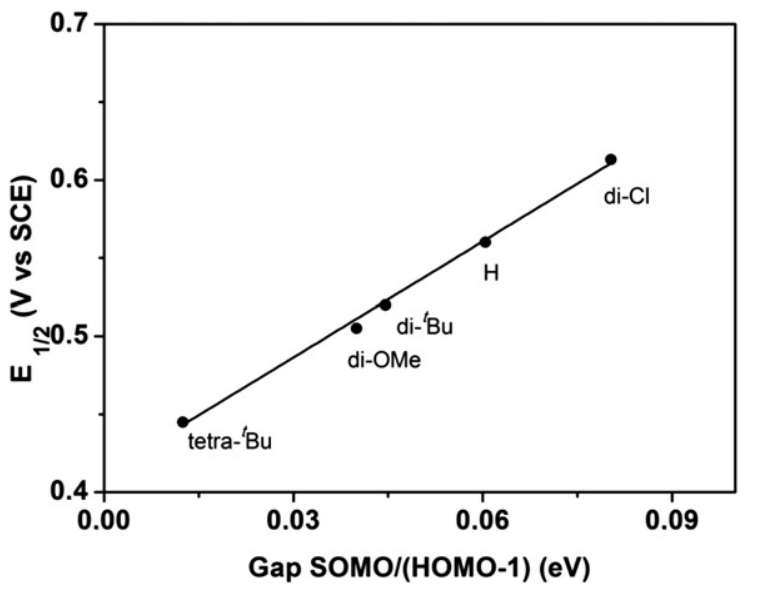

Fig. 15. Correlation between $\mathrm{V}^{\mathrm{IV}} / \mathrm{V}^{\mathrm{V}}$ oxidation potential and the SOMO/HOMO-1 energy gap for VO (X,Y)salophen optimized geometries (DFT/B3LYP/6-31G+(d,p)).

\section{Conclusions}

Electronic characterization of vanadyl-salophen complexes has been performed in terms of absorption spectra, electrochemical behavior, and theoretical calculations. The obtained results provide new insights for understanding the factors (i.e. substituents, rigidity of the ligand, steric and solvent effects) that influence the electronic density of vanadium atom. Moreover the DFT calculations allow visualizing the molecular orbital involved directly in the electronic transitions in UV/Vis region. The electronic configuration for this class of compounds is strictly related to the application of interest, and these results can be useful to indicate the appropriate combination of skeletonsubstituents on vanadyl complexes for the different requirements.

\section{Acknowledgments}

Cost Actions CM1003 "Biological oxidation reactions-mechanisms and design of new catalysts" and CM1205 "Catalytic Routines for Small Molecule Activation (CARISMA)" are acknowledged for having allowed a stimulant European Research Environment and the exchange of young researchers between networks labs, and PRIN 2010-2011 project 2010FM738P for funding support.

\section{Appendix A. Supplementary data}

Supplementary data to this article can be found online at http://dx. doi.org/10.1016/j.jinorgbio.2015.03.003.

\section{References}

[1] N.D. Chasteen, Vanadium in Biological Systems, Physiology and Biochemistry, Kluwer Academic Publishers, Dordrecht, The Netherlands, 1990.

[2] A. Tracey, Vanadium Compounds, ACS Symposium Series, American Chemical Society, Washington, DC, 1998.

[3] D.C. Crans, J.J. Smee, E. Gaidamauskas, L. Yang, Chem. Rev. 104 (2004) 849-902.

[4] T. Punniyamurthy, S. Velusamy, J. Iqbal, Chem. Rev. 105 (2005) 2329-2363.

[5] V. Conte, A. Coletti, B. Floris, G. Licini, C. Zonta, Coord. Chem. Rev. 255 (2011) 2165-2177.

[6] V. Conte, A. Coletti, M. Mba, C. Zonta, G. Licini, Coord. Chem. Rev. 255 (2011) 2345-2357.

[7] I.E. Wachs, Dalton Trans. 42 (2013) 11762-11769.

[8] R.R. Moskalyk, A.M. Alfantazi, Miner. Eng. 16 (2003) 793-805

[9] A. Coletti, P. Galloni, A. Sartorel, V. Conte, B. Floris, Catal. Today 192 (2012) 44-55

[10] A. Coletti, C.J. Whiteoak, V. Conte, A.W. Kleij, ChemCatChem 4 (2012) 1190-1196.

[11] P. Zabierowski, J. Szklarzewicz, R. Grybos, B. Mordryl, W. Nitek, Dalton Trans. 43 (2014) 17044-17053.

[12] P.G. Cozzi, Chem. Soc. Rev. 33 (2004) 410-421.

[13] P.G. Cozzi, L.S. Dolci, A. Garelli, M. Montalti, L. Prodi, N. Zaccheroni, New J. Chem. 27 (2003) 692-697.

[14] K.Y. Hwang, H. Kim, Y.S. Lee, M.H. Lee, Y. Do, Chem. Eur. J. 15 (2009) 6478-6487.

[15] D. Xie, J. Jing, Y.-B. Cai, J. Tang, J.-J. Chen, J.-L. Zhang, Chem. Sci. 5 (2014) 2318-2327.

[16] V. Béreau, V. Jubéra, P. Arnaud, A. Kaiba, P. Guionneaud, J.-P. Sutter, Dalton Trans. 39 (2010) 2070-2077.

[17] P. Galloni, A. Coletti, B. Floris, V. Conte, Inorg. Chim. Acta 420 (2014) 144-148.

[18] D.M. Boghaei, S. Mohebi, Tetrahedron 58 (2002) 5357-5366.

[19] C.J. Chang, J.A. Labinger, H.B. Gray, Inorg. Chem. 36 (1997) 5927-5930.

[20] E. Carter, I.A. Fallis, D.M. Murphy, D.J. Willock, S. Van Doorslaer, E. Vinck, Chem. Phys. Lett. 486 (2010) 74-79.

[21] M.P. Weberski, C.C. McLauchlan, C.G. Hamaker, Polyhedron 25 (2006) 119-123.

[22] M. Salavati-Niasari, A. Badiei, K. Sabyeryan, Chem. Eng. J. 173 (2011) 651-658.

[23] E. Tsuchida, K. Yamamoto, K. Oyaizu, N. Iwasaki, F.C. Anson, Inorg. Chem. 33 (1994) 1056-1063.

[24] T.B. Zid, I. Keheder, A. Ghorbel, React. Kinet. Mech. Catal. 100 (2010) 131-143.

[25] J. Zhao, W. Wang, Y. Zhang, J. Inorg. Organomet. Polym. 18 (2008) 441-447.

[26] M.J. Frisch, G.W. Trucks, H.B. Schlegel, G.E. Scuseria, M.A. Robb, J.R. Cheeseman, G. Scalmani, V. Barone, B. Mennucci, G.A. Petersson, H. Nakatsuji, M. Caricato, X. Li, H.P. Hratchian, A.F. Izmaylov, J. Bloino, G. Zheng, J.L. Sonnenberg, M. Hada, M. Ehara, K. Toyota, R. Fukuda, J. Hasegawa, M. Ishida, T. Nakajima, Y. Honda, O. Kitao, H. Nakai, T. Vreven, J.A. Montgomery Jr., J.E. Peralta, F. Ogliaro, M. Bearpark, J.J. Heyd, E. Brothers, K.N. Kudin, V.N. Staroverov, R. Kobayashi, J. Normand, K. Raghavachari, A. Rendell, J.C. Burant, S.S. Iyengar, J. Tomasi, M. Cossi, N. Rega, J.M. Millam, M. Klene, J.E. Knox, J.B. Cross, V. Bakken, C. Adamo, J. Jaramillo, R. Gomperts, R.E. Stratmann, O. Yazyev, A.J. Austin, R. Cammi, C. Pomelli, J.W. Ochterski, R.L. Martin, K. Morokuma, V.G. Zakrzewski, G.A. Voth, P. Salvador, J.J. Dannenberg, S. Dapprich, A.D. Daniels, O. Farkas, J.B. Foresman, J.V. Ortiz, J. Cioslowski, D.J. Fox, Gaussian 09, Revision A.02, Gaussian, Inc., Wallingford CT, 2009.

[27] A.D. Becke, J. Chem. Phys. 98 (1993) 5648-5652.

[28] C. Lee, W. Yang, R.G. Parr, Phys. Rev. B 37 (1988) 785-789.

[29] A.H. Kianfar, S. Mohebbi, J. Iran. Chem. Soc. 4 (2007) 215-220.

[30] L.P. Hammett, Physical Organic Chemistry, 2nd ed. Mc Graw-Hill, New York, 1970. 367.

[31] A. Erçă̆, M. Şahin, A. Koca, E. Bozkurt, J. Coord. Chem. 66 (2013) 1635-1649.

[32] Y. Yang, M.N. Weaver, K.M. Merz, J. Phys. Chem. A 113 (2009) 9843-9851.

[33] M.M. Quintal, A. Karton, M.A. Iron, A.D. Boese, J.M.L. Martin, J. Phys. Chem. A 110 (2006) 709-716.

[34] P.J. Hay, W.R. Wadt, J. Chem. Phys. 82 (1985) 299-310. 